\title{
MENGHASRATI SANG AKHIR, MEMPERSEMBAHKAN DIRI PADA DUNIA
}

\author{
Christanto Sema Rappan Paledung*
}

\begin{abstract}
Abstrak: Artikel ini membahas Teologi Hari Kedelapan sebagai sumber berteologi yang solid untuk mempercakapkan peran gereja dalam ruang publik. Teologi Hari Kedelapan menegaskan bahwa pada Hari Kedelapan yakni hari Kebangkitan Kristus adalah permulaan dunia baru. Dengan demikian, gagasan ini mencakup percakapan liturgis, eskatologis, eklesiologis, penciptaan, dan sebagainya. Percakapan dalam makalah ini juga melibatkan konsep person dan eros dari Christos Yannaras. Yannaras menegaskan bahwa person merupakan konstitusi yang relasional. Sebab itu, kehadirannya hanya dapat diwujudkan dalam gerak yang erotik. Untuk menegaskan kehadiran gereja dalam ruang publik, saya berargumen bahwa dengan konsep person dan eros, Hari Kedelapan merupakan gerak erotik Allah kepada dunia.
\end{abstract}

Kata-kata kunci: Hari Kedelapan, eskatologi, eklesiologi, person, eros, teologi publik.

Abstract: This article discusses Theology of the Eighth Day as a solid theological source to promote the role of the church in the public sphere. The theology asserts that the Eighth Day as the day the Resurrection of Christ is the beginning of a new world. Thus, this idea includes liturgy, eschatology, ecclesiology, creation, etc. Conversations in this paper also involve the concept of person and eros from Christos Yannaras. Yannaras emphasized thatperson is a relational constitution. Therefore, its presence can only realize in erotic movements. To underline the presence of the church in the public sphere, I argue that with the concepts of person and eros, The Eighth Day is Godss erotic motion to the world.

Keywords: The Eighth Day, eschatology, ecclesiology, person, eros, public theology.

* Christanto Sema Rappan Palendung, Sekolah Tinggi Filsafat Teologi, Jl. Proklamasi No.27, Pegangsaan, Menteng, Jakarta. E-mail: rappanpaledung@gmai.com. 


\section{PENDAHULUAN}

... the first and eighth day shows that this connection of the Eucharist with time emphasizes the eschatological nature of the Eucharist, the manifestation in it of the Lord's Day, the New Aeon. The Eucharist is the Sacrament of the Church. It is the Parousia, the presence of the Risen and Glorified Lord in the midst of "His own," those who in Him constitute the Church and are already "not of this world" but partakers of the new life of the New Aeon. ${ }^{1}$

Teologi Hari Kedelapan merupakan sumber teologis yang sangat jarang dipercakapkan dalam kekristenan Global. Teologi ini dapat ditemukan dalam korpus Bapa-bapa Gereja. Namun, sampai hari ini, praktis hanya tradisi Gereja Ortodoks yang masih memelihara gagasan teologis tersebut. ${ }^{2}$ Hari Kedelapan merupakan konsep yang mencakup percakapan liturgis, eskatologis, eklesiologis, penciptaan, dan sebagainya. Makalah ini akan mencoba menilik percakapan hari Kedelapan tersebut dan mencari signifikansinya dengan percakapan eklesiologi hari ini. Makalah ini juga akan membaca konsep hari Kedelapan ini dengan menggunakan perspektif person dan eros dalam pemikiran Christos Yannaras untuk me-

1 Alexander Schmemann, Introduction to Liturgical Theology (Crestwood, N.Y: St. Vladimir's Seminary Press, 2003), 80.

2 Dalam amatan sebuah singkat, saya menemukan setidaknya dua teolog Protestan abad 20 yang sedikit mempercakapkan teologi Hari Kedelapan, yakni Jürgen Moltmann dan Wolfhart Pannenberg. Moltman menjelaskankan teologi Hari Kedelapan dalam bagian apendiks God in Creation yang berjudul Sunday: The Feast of the Beginning. Ia menegaskan bahwa jika puncak perayaan liturgi gerejawi adalah kebangkitan Kristus, maka sangatlah beralasan bahwa Hari Kedelapan atau hari Minggu sebagai hari yang mengantisipasi akhir dari waktu sekaligus awal dari penciptaan baru. Bahkan, ia meyakini bahwa penciptaan baru hanya terjadi di dalam kebangkitan Yesus Kristus dari kematian Jürgen Moltmann, God in Creation: A New Theology of Creation and the Spirit of God (London: SCM Press Ltd, 1985), 295-295."number-of-pages:"'"388,"'"source:"'Google Books,"'"event-place:"'"London,"'"abstract:"'"The title expresses the book's intention: not to go on distinguishing between God and the world, so as then to surrender the world, as godless, to its scientific 'disenchantment' and its technical exploitation by human beings, but instead to discover God in all the beings he has created and to find his life-giving Spirit in the community of creation that they share. This view ¿which has also been called panentheistic (in contrast to pantheistic. Sementara itu, Pannenberg dalam Systematic Theology 2-nya, menjelaskan teologi hari Kedelapan dalam The Creation of the World. Ia mengatakan bahwa pengharapan apokaliptik terkait penyempurnaan eskatologis dunia merujuk pada penciptaan hari kedelapan, sebagai hari pertama dalam satu minggu yang juga adalah awal dari penciptaan oleh Allah. Ia juga merujuk pada Clement dari Alexandria (150-215 ZB) Wolfhart Pannenberg, Systematic Theology (A\&C Black, 2004), 144-45. 
negaskan peran gereja dalam ruang publik.

Tesis saya dalam makalah ini adalah bahwa Hari Kedelapan memusatkan diri pada gerak erotik ilahi yang merengkuh dunia, sebab itu gereja merupakan peziarah kepada Sang Akhir, yang berpartisipasi secara erotik dalam ruang publik. ${ }^{3}$ Makalah ini terbagi dalam tiga bagian. Bagian pertama akan menilik sejumlah teks-teks Bapa Gereja yang mempercakapkan konsep Hari Kedelapan, seperti Surat Barnabas, Ignatius dari Antiokhia, Justin Martir, dan Basil Agung. Kedua, saya akan membahas pemikiran Christos Yannaras yang mengelaborasi nisbah antara person dan eros. Bagian ketiga akan mengeksplorasi teologi Hari Kedelapan dengan mempergunakan perspektif yang diusulkan oleh Yannaras, sekaligus menegaskan signifikansinya dalam percakapan gereja dalam ruang publik.

\section{TEOLOGI HARI KEDELAPAN DALAM KORPUS BAPA-BAPA GEREJA}

Bagian ini hendak membahas sejumlah teks Bapa Gereja yang mempercakapkan konsep hari Kedelapan dengan sangat mendalam, yakni Surat Barnabas, Ignatius dari Antiokhia, Justin Martir dan Basil Agung. Selain Bapa-bapa Gereja tersebut, ada Bapa Gereja lainnya yang membahas Hari Kedelapan ini, seperti Cyril dari Alexandria (378-444 ZB), Gregory dari Nyssa (335-394 ZB), Maximus Sang Pengaku (580-662 ZB), dan lain-lain. Oleh karena makalah ini sangat terbatas, maka saya membatasi pembahasan tentang teologi Hari Kedelapan hanya pada beberapa aspek saja.

Istilah Hari Kedelapan pertama kali muncul dalam korpus Surat Barnabas (100 ZB). Dalam "Chapter XV: The False and the True Sabbath," penulis surat ini mengatakan: ... I shall make a beginning of the eighth

3 Lihat Nindyo Sasongko, "Eros, Eklesia, dan Resistensi: Sebuah Eksplorasi KonstruktifMisiologis Peran Gereja di Ruang Publaik." Tulisan Sasongko ini tampaknya menjadi satu-satu teks teologi Indonesia yang mencoba membaca ulang konsep eros dan relasinya dengan eklesiologi. Ia mengkritik pemikiran Andres Nygren yang membuat hierarki konsep cinta Yunani, yakni agape, eros, filia, dan storge Nindyo Sasongko, "Eros, Eklesia, dan Resistensi: Sebuah Eksplorasi Konstruktif-Misiologis Peran Gereja di Ruang Publik," dalam Misiologi Kontemporer: Merentangkan Horison Panggilan Kristen, ed. oleh C.S. Rappan Paledung, Nindyo Sasongko, dan Indah Sriulina (Jakarta: BPK Gunung Mulia \& Asosiasi Teolog Indonesia, 2019), 243-70. 

day (tebal dari saya), that is, a beginning of another world. Wherefore, also, we keep the eighth day with joyfulness, the day also on which Jesus rose again from the dead. And when He had manifested Himself, He ascended into the heavens. ${ }^{4}$

Kedatangan Sang Putra membuat kejahatan tidak akan ada lagi. Allah akan memulai segala sesuatunya pada hari Kedelapan. Hari Kedelapan sebagai hari kebangkitan Kristus merupakan awal dunia yang baru dan akan terus diperlihara dengan penuh kesukacitaan. ${ }^{5}$ Konsep yang ditawarkan oleh Barnabas sendiri merujuk kepada dunia baru atau eskatologi dengan menempatkan Kristus sebagai penanda dimulai kehidupan baru bersama Allah.

Penulis sezamannya juga membicarakan hari Kedelapan. Ignatius dari Antiokhia, misalnya, mengatakan agar umat memelihara hari Tuhan atau Hari Kedelapan sebagai sebuah perayaan akan hari kebangkitan dan puncak dari semua hari (dalam satu minggu). ${ }^{6}$ Selain dipahami sebagai hari kebangkitan, Hari Kedelapan juga dipahami sebagai hari pertama dalam satu minggu dan diyakini juga sebagai hari dimulainya penciptaan. Sebab itu, hari Kedelapan juga erat kaitannya dengan penciptaan kedua. Selain itu, Justin Martir (100-165 ZB) yang juga sezaman dengan Surat Barnabas dalam Dialogue with Trypho XXIII: 4-5 mengatakan:

4: Indeed, while Abraham himself was still uncircumcised, he was justified and blessed by God because of his faith in him, as the Scriptures tell us. Furthermore, the Scriptures and the facts of the case force us to admit that Abraham received circumcision for a sign, not for justification itself. Thus, it was justly said of your people, that soul which shall not be circumcised on the eighth day (tebal dari saya) shall be destroyed out of his people. 5: Moreover, the fact that females cannot receive circumcision of the flesh shows that circumcision was given as a sign, not as an act of justification. For God also bestowed on women the capability of performing every good and virtuous act. We see that the physical formation of male and female is different, but it is equally

4 Philip Schaff dkk., Ante-Nicene Fathers, 2017, 395.

5 Alexander Roberts dkk., Ante-Nicene Fathers: The Writings of the Fathers down to A.D. 325 (Peabody, Mass.: Hendrickson Publishers, 1994), 394-95.

6 Schaff dkk., Ante-Nicene Fathers, 175. 
evident that the bodily form is not what makes either of them good or evil. Their righteousness is determined by their acts of piety and justice.

Justin menolak ketaatan kepada Sabat dengan menggunakan sunat sebagai argumentasinya. Menurutnya, tanda perjanjian Allah dengan Abraham bukanlah pada perayaan Sabat, tetapi pada sunat yang dilaksanakan pada hari kedelapan setelah kelahiran (XXIII:4). Meskipun demikian, Justin mengakui bahwa sunat tidak memadai, karena sunat hanya dapat dilakukan pada laki-laki (XXIII:5). ${ }^{7}$ Ia memberikan makna baru pada sunat Israel, yakni sebagai kehidupan baru di dalam Kristus. Dalam pasal CXXXVIII:1 (Noah is a figure of Christ, who has regenerated us by water, and faith, and wood: (i.e., the cross.)), Justin mengatakan:

...God has said in Isaiah to Jerusalem: 'I saved thee in the deluge of Noah.' By this which God said was meant that the mystery of saved men appeared in the deluge. For righteous Noah, along with the other mortals at the deluge, i.e., with his own wife, his three sons and their wives, being eight in number, were a symbol of the eighth day, wherein Christ appeared when He rose from the dead, forever the first in power. For Christ, being the first-born of every creature, became again the chief of another race regenerated by Himself through water, and faith, and wood, containing the mystery of the cross; even as Noah was saved by wood when he rode over the waters with his household. Accordingly, when the prophet says, 'I saved thee in the times of Noah,' as I have already remarked, he addresses the people who are equally faithful to God, and possess the same signs. For when Moses had the rod in his hands, he led your nation through the sea. And you believe that this was spoken to your nation only, or to the land. But the whole earth, as the Scripture says, was inundated, and the water rose in height fifteen cubits above all the mountains: so that it is evident this was not spoken to the land, but to the people who obeyed Him: for whom also He had before prepared a resting-place in Jerusalem, as was previously demonstrated by all the symbols of the deluge; I mean, that by water, faith, and wood, those who are afore-prepared, and who repent of the sins which they have committed, shall escape from the

7 Justin, Dialogue with Trypho, ed. oleh Michael Slusser, trans. oleh Thomas B. Falls, Selections from the Fathers of the Church, v. 3 (Washington, D.C: Catholic University of America Press, 2003), 39. 

impending judgment of God.

Justin memahami bahwa delapan orang anggota keluarga Nuh merujuk kepada penciptaan Hari Kedelapan. Air bah dipahami sebagai pembersihan Allah akan dunia ini, dan delapan orang yang selamat dari peristiwa tersebut adalah simbol re-kreasi Allah. Peristiwa tersebut kemudian diinterpretasikan Justin sebagai penciptaan kedua melalui kebangkitan Kristus. Pada ayat 2, Justin menandaskan bahwa kebangkitan Kristus merupakan the first-born of every creature. Sebab itu, melalui Kristus, seluruh ciptaan diciptakan kembali yang terselenggara melalui misteri salib dan kebangkitan. ${ }^{8}$

Basilius Agung (330-379 ZB) merupan salah satu Bapa Kapadokia, bersama dengan Gregorius Nazianzus dan Gregorius dari Nyssa. Dalam Hexameron II:8, Basil mengatakan:

The day of the Lord (tebal dari saya) is darkness and not light. A day of darkness for those who are worthy of darkness. No; this day without evening, without succession and without end is not unknown to Scripture, and it is the day that the Psalmist calls the eighth day (tebal dari saya), because it is outside this time of weeks. Thus whether you call it day, or whether you call it eternity, you express the same idea. Give this state the name of day; there are not several, but only one. If you call it eternity still it is unique and not manifold. Thus it is in order that you may carry your thoughts forward towards a future life (tebal dari saya), that Scripture marks by the word "one" (tebal dari saya) the day which is the type of eternity, the first fruits of days, the contemporary of light, the holy Lord's day (tebal dari saya) honoured by the Resurrection of our Lord. ${ }^{9}$

Pada bagian tersebut, Basil menegaskan bahwa Hari Kedelapan melampaui hari-hari lain dalam satu minggu, karena ia adalah representasi kekekalan. Di dalam Hexameron II:8, Basil menafsirkan Kejadian 1:5, yang berbunyi, “Dan Allah menamai terang itu siang dan gelap itu malam. Jadilah petang dan jadilah pagi, itulah hari pertama." Menurutnya, malam (evening) merupakan batas antara siang dan malam (night).

8 Justin, 207.

9 Philip Schaff, Nicene and Post-Nicene Fathers, 2nd Series, vol. VIII: St. Basil: Letters and Select Works (Eerdmans, 1968), 274. 
Malam baru diciptakan pada hadir kedua setelah Allah memisahkan siang dan malam. Maka, Basil menyebut satu hari dan bukan hari pertama. Kisah penciptaan Alkitab menyaksikan satu hari sebagai hari yang kekal. Hari Allah tersebut adalah hari kegelapan atau malam. Pemazmur menyebutkan hari tersebut adalah hari Kedelapan karena berada di luar hari-hari biasa dalam satu minggu. Hari Kedelapan juga dapat disebut sebagai hari atau kekekalan. ${ }^{10} \mathrm{Hal}$ yang serupa juga ditegaskannya dalam On the Holy Spirit XXVII: 66,

On the day of the resurrection, we remind ourselves of the grace given to us by standing at prayer, not only because we rose with Christ, and are bound to "seek those things which are above," but because the day seems to us to be in some sense an image of the age which we expect, wherefore, though it is the beginning of days (tebal dari saya), it is not called by Moses first, but one (tebal dari saya). For he says "There was evening, and there was morning, one day," as though the same day often recurred. Now "one" and "eighth" (tebal dari saya) are the same, in itself distinctly indicating that really "one" and "eighth" of which the Psalmist makes mention in certain titles of the Psalms, the state which follows after this present time, the day which knows no waning or eventide, and no successor, that age which endeth not or groweth old. ${ }^{11}$

Jean Danielou mengatakan bahwa penegasan Basil tentang Hari Kedelapan bukan hanya pada kebangkitan Kristus, melainkan juga pada representasi Kerajaan Allah dalam kebangkitan tersebut. ${ }^{12}$ Hari Tuhan memang dipahami sebagai hari kebangkitan, tetapi juga sebagai waktu (one day) yang kembali pada ketujuh hari lainnya. Bentuk ini merupakan siklus yang memiliki awal dan akhir dengan sendirinya. Hari Kedelapan ini tidak akan pernah berakhir. Menurut Danielou, Hari Kedelapan dipahami merupakan hari yang meresap ke dalam hari-hari biasa. ${ }^{13}$ Gagasan kemeresapan ini penting untuk memberi ruang pada dimensi keseharian dan segala kompleksitasnya. Menariknya, dalam teologi Gereja Orto-

10 Schaff, 273-74.

11 Schaff, 231.

12 Jean Daniélou, The Bible and the Liturgy, 1 ed. (Notre Dame, Indiana: University of Notre Dame Press, 2002), 263.

13 Daniélou, 264. 
226 Menghasrati Sang Akhir, Mempersembahkan Diri pada Dunia (Ch. Sema Rappan P.) doks, Alexander Schmeman, misalnya, menolak pemisahan antara sacred dan profane. Artinya, ruang-ruang sekuler berada dalam cakupan yang sacred. Schmeman mengatakan bahwa ruang-ruang sekuler tersebut berada dalam cakupan misteri Paska. ${ }^{14}$

Bertolak dari pemikiran Basil, Mario Baghos menegaskan bahwa seluruh dunia yang telah diciptakan sejak hari pertama penciptaan akan ditransfigurasikan pada waktu akhir. Bahkan menurutnya, teks Basil yang menginterpretasi teks penciptaan dalam Kejadian menegaskan bahwa seluruh proses penciptaan Allah direkapitulasikan ke dalam kebangkitan Kristus pada Hari Kedelapan. Sebuah hari yang secara paradoksal melampaui tujuh hari penciptaan dan sekaligus menegaskan watak eskatologisnya. Sebab itu, diperlukan partisipasi yang terus-menerus, sebagai bentuk dari cerapan eskatologi. ${ }^{15}$

Basil mengatakan bahwa doa sebagai bagian dari praktik monastik selalu mengingatkan umat kepada anugerah yang tercurah pada hari kebangkitan atau hari pertama, seolah-olah umat dibangkitkan untuk bersama dan dihisabkan ke dalam Kristus untuk mengecap keilahian. Sebab itu, ia menasihatkan gereja untuk mengajar umat tetap berdoa pada hari-hari biasa, sehingga umat tidak lalai terhadap ketentuanketentuan bagi peziarahan menuju kehidupan abadi. Tata cara tersebut menandaskan agar umat mengarahkan pikirannya sekarang ke masa depan. ${ }^{16}$ Meskipun, kekristenan Timur menolak pemisahan ruang religius dan sekuler, mereka tidak naif terhadap kondisi real masyarakat. Sebab itu, Basil mengatakan perlunya tata cara dan doa agar tetap membuat umat terarah pada misteri Paska. Tampaknya, upaya untuk menegaskan kerikatan Hari Kedelapan dan hari-hari biasa.

Berdasarkan pemaparan di atas, saya mencoba untuk merumuskan secara ringkas teologi hari Kedelapan. Pertama, hari Kedelapan adalah

14 Alexander Schmemann, For the life of the world: sacraments and orthodoxy (Crestwood, N.Y: St. Vladimir's Seminary Press, 2004).

15 Mario Baghos, "St Basil's Eschatological Vision: Aspects of the Recapitulation of History and the 'Eighth Day,'" Phronema 25 (2010): 85-103.

16 Basil, On the Holy Spirit, trans. oleh Stephen M. Hildebrand, Popular Patristics Series, no. 42 (Yonkers, N.Y: St. Vladimir's Seminary Press, 2011), 106. 
pemaknaan ulang Bapa-bapa Gereja terhadap konsep sunat dalam tradisi Israel. Jika Israel memahami sunat sebagai inisiasi, pemurnian, dan tanda perjanjian Allah dengan Abraham, maka Bapa-bapa gereja memahami sebagai kehidupan baru di dalam Kristus. Kedua, Hari Kedelapan dipandang sebagai hari kebangkitan Kristus, sekaligus imaji terhadap Kerajaan Allah yang ada di masa depan. Sebab itu, dimensi penciptaan pada Hari Kedelapan erat kaitannya dengan dunia baru atau kerajaan Allah (Zizioulas 2011, 55). Dengan kata lain, Hari Kedelapan berwatak eskatologis.

Ketiga, secara eklesiologis,Hari Kedelapanberdampakpadakonstitusi hakikat gereja. Dalam Being as Communion, Zizoulas mengatakan bahwa konstitusi gereja adalah Kristus. ${ }^{17}$ Singkatnya, kebangkitan Kristus yang adalah penciptaan baru dan imaji Kerajaan Allah berdampak pada tugas dan panggilan gereja di dunia. Keempat, Hari Kedelapan melampaui hari-hari biasa bahkan tidak berujung. Alexander Schmeman mengatakan bahwa implikasi hari Kedelapan dalam perspektif kemewaktuan adalah bahwa gereja berpartisipasi dalam kehidupan baru (New Aeon) di dalam keseharian. ${ }^{18}$ Sebagaimana dielaborasi dalam teks-teks Bapa-bapa Gereja, eskatologi sebagai konsekuensi dari Hari Kedelapan menegaskan wajah kesehariannya pada dua hal. Yang pertama terletak pada watak kekekalannya. Kekekalan penting dalam konsep ini mengingat bahwa Hari Kedelapan melampaui dan bahkan merupakan puncak hari-hari lainnya. Yang kedua terlihat pada watak sirkularitas yang membuat Hari Kedelapan semestinya dialami di dalam hari-hari biasa. Pada bagian berikutnya, saya akan menjelaskan pemikiran Christos Yannaras yang memaparkan konsep person dan eros. Pemikirannya akan saya gunakan untuk membaca teologi Hari Kedelapan dan implikasinya dengan peran gereja dalam ruang publik.

17 John D. Zizioulas, Being as communion: studies in personhood and the church, Contemporary Greek theologians, no. 4 (Crestwood, N.Y: St. Vladimir's Seminary Press, 1985), 139.

18 Schmemann, Introduction to Liturgical Theology, 80. 

KONSEP PERSON DAN EROS MENURUT CHRISTOS YANNARAS

Bagaimana menghasrati Hari Kedelapan? Mengapa harus menghasrati Hari Kedelapan? Untuk merespons pertanyaan-pertanyaan tersebut, saya akan menilik pemikiran Christos Yannaras. Andrew Louth mengatakan bahwa Yannaras merupakan teolog Ortodoks Yunani paling penting yang masih hidup. ${ }^{19}$ Bahkan, Jonathan Cole mengatakan bahwa Yannaras adalah figur kontroversial dalam teologi Ortodoks Yunani. Karyanya dalam teologi mengejutkan dan cermerlang meskipun keterlibatannya dengan teolog Ortodoks lainnya sedikit. Yannaras mengkritik Gereja Ortodoks Yunani dan retorikanya yang terkadang imun terhadap sesuatu yang berbeda dari dirinya. Karyanya yang paling kontroversial adalah The Freedom of Morality, bahkan sempat menimbulkan perselisihan pada penerbitannya pada tahun 1970 dan dikecam secara publik melalui televisi. $^{20}$

Yannaras merupakan teolog Ortodoks yang secara serius mempercakapkan konsep prospon atau person dan konsep eros. Salah satu karyanya yang tersohor adalah Person and Eros, yang diterbitkan berdasarkan karya disertasinya yang berjudul The Ontological Content of the Theological Notion of Personhood. ${ }^{21}$ Rowan Williams mengatakan bahwa upaya Yannaras adalah sintesis tradisi patristik Yunani dengan pemikiran fenomenologis modern. Bahkan karya sebelumnya, The Theology of the Absence and Ignorance of God (1967), telah menampilkan upaya yang serupa, yakni komparasi tradisi apofatik Bizantium dengan konsep nothingness dalam pemikiran Martin Heidegger. ${ }^{22}$ Pada bagian ini, saya hanya akan berfokus pada eksplorasi Yannaras tentang person dan eros.

19 Andrew Louth, "Introduction," dalam On the Absence and Unknowability of God: Heidegger and the Areopagite, oleh Christos Yannaras, trans. oleh Haralambos Ventis, 2nd ed. (London ; New York: T \& T Clark International, 2005), 1.

20 Jonathan Cole, "Personhood, Relational Ontology, and the Trinitarian Politics of Eastern Orthodox Thinker Christos Yannaras," Political Theology 0, no. 0 (22 Februari 2017): 2-3.

21 Disertasi ini diraih di University Salonika, Athens pada tahun 1970 dengan judul To Prosopo kai o Eros (Person and Eros).

22 Rowan Williams, "The Theology of Personhood: A Study of the Thought of Christos Yannaras," Sobornost 6 (1972): 415. 


\section{EROS DAN PERSON}

Menurut Yannaras, percakapan tentang apofatisme Gereja Timur berujung pada pembacaan dua person Trinitas, Yesus Kristus dan Roh Kudus, sebagai tropos hyparxeos atau cara mengada (mode of existence) Allah, sebagaimana yang digagas oleh Bapa-bapa Kapadokia. ${ }^{23}$ Penanda dari eksistensi person adalah self-conciousness dan otherness. Kesadaran penuh diri menegaskan eksistensi "Aku" yang beridentitas yang berbeda dari yang lain (otherness). Perbedaan tersebut merupakan karakter keliyanan yang absolut, unik, berbeda, tidak dapat diulang. ${ }^{24}$ Dari teologi apofatismelah Yannaras berangkat untuk membahas gagasan person yang hipostatik dan ekstatik. ${ }^{25}$ Apofatisme menolak segala bentuk gagasan yang mereduksi Allah ke dalam sebuah konsep, itulah yang memungkinkan pengetahuan dan pertautan dengan Allah. Peristiwa tersebut oleh Yannaras disebut sebagai peristiwa eros atau erotik. Eros merupakan jalan tertinggi untuk menuju pengetahuan person karena eros adalah penerimaan terhadap yang lain (baca person) secara keseluruhan. ${ }^{26}$

Secara epistemologis, kenyataan apofatik merujukan kepada eksistensi kebenaran dalam konteks relasi dengan yang lain. Sebab itu, terma yang paling tepat untuk menggambarkan person yang relasional adalah eros. Sotiris Mitralexis mengatakan bahwa, dalam pemikiran Plato, pengetahuan yang ultima adalah eros. Eros merupakan hubungan yang bebas dari egosentrisme dan mampu mempersembahkan diri kepada yang lain. $^{27}$

Person merupakan pengungkapan being. Baginya, eksistensi person harus bersifat ekstasis (ec-static), atau kemampuan untuk berdiri (baca:

23 Christos Yannaras, Person and Eros, trans. oleh Norman Russell (Brookline, Mass: Holy Cross Orthodox Press, 2007), 19-20.

24 Christos Yannaras, Elements of Faith: An Introduction to Orthodox Theology (Edinburgh: T \& T Clark, 1991), 29.

25 Berbeda dari John D. Zizioulas, Yannaras mendasarkan percakapan teologisnya pada pemikiran Gregorius Palamas yang membedakan antara esensi Allah dan energi Allah. Yannaras, 43. bdk. John D. Zizioulas, The Eucharistic Communion and the World (London ; New York: T \& T Clark, 2011)..

26 Christos Yannaras, The Freedom of Morality, Contemporary Greek Theologians, no. 3 (Crestwood, N.Y: St. Vladimir's Seminary Press, 1984), 23.

27 Sotiris Mitralexis, "Person, Eros, Critical Ontology: An Attempt to Recapitulate Christos Yannaras' Philosophy," Sobornost 34, no. 1 (2012): 36. 

relasi) di luar dirinya. Ekstasis diidentifikasikan sebagai aktualisasi diri terhadap orang lain. ${ }^{28}$ Menurutnya, ekstasi manusia merupakan rekapitulasi dan transendensi-diri dari esensi. Artinya, aktualisasi diri hanya termanifestasi melalui energi. ${ }^{29}$ Ada (beings) memperlihatkan keunikan personal yang tersingkap melalui kehadiran dan energi yang kreatif. ${ }^{30}$ Maka, hasrat dalam diri manusia bukan untuk dirinya sendiri, tetapi juga untuk orang lain (other) yang termanifestasikan melalui eros. ${ }^{31}$

Secara etimologis, person berasal dari kata Yunani prosopon yang berasal dari kata pros yang berarti towards dengan ops (bentuk genetif) yang berarti mata atau wajah. Sebab itu, prosopon berarti berhadapan dengan seseorang atau sesuatu. Maka, menurut Yannaras, prosopon tidak dapat diinterpretasikan sesederhana individu, karena individu terpisah dari relasi. Person adalah beingoppsite-someone/something. Singkatnya, relasi merupakan konstitusi dari person itu sendiri. ${ }^{32}$ Yannaras menjadikan konsep person sebagai anti tesis dari konsep individualitas yang antirelasional.

Ia lebih lanjut menegaskan bahwa person bukanlah hakikat yang terdeterminasi, melainkan tentang bagaimana ia mengada. Person adalah mengada. Anthony Kaniaru mengatakan bahwa Yannaras berhutang pada konsep personhood yang dikembangkan oleh Vladimir Lossky. Menurut Lossky, personhood dalam teologi Ortodoks dipahami sebagai ekstatik (freedom from self for God) dan hipostatik (unik) yang didasarkan pada teologi apofatik, meskipun Lossky tidak meneruskan dalam pemikirannya mengenai relasi antara person dan relasionalitas. Selanjutnya, bersama dengan John D. Zizioulas, teolog Ortodoks modern lainnya, Yannaras mengembangkan konsep personhood Trinitas sebagai gerak ekstasis, hipostatik, dan relational..$^{33}$

28 Yannaras, Person and Eros, 20.

29 Yannaras, 223.

30 Yannaras, 81.

31 Yannaras, 20.

32 Yannaras, 1.

33 Antony Kaniaru, "Rethinking Rationality: Theological Anthropology in light of Profound Cognitive Impairment, Relationality, Embodiment and Personhood" (Doctoral Dissertation, Durham University, 2012), 94. 
Bagi Yannaras, Trinitas memiliki kesamaan dengan person sebagai peristiwa relasional. Person sendiri adalah adalah pengungkapan being. Baginya, eksistensi person harus bersifat ekstasis (ec-static), atau kemampuan untuk berdiri (baca: relasi) di luar dirinya. Ekstasis diidentifikasikan sebagai aktualisasi diri terhadap orang lain. ${ }^{34}$ Pembedaan esensi dan energi juga digunakan dalam percakapan ini. Ekstasi manusia merupakan rekapitulasi dan transendensi-diri esensi. Artinya, aktualisasi diri hanya manifestasikan melalui energi dari esensi. ${ }^{35}$ Hasrat dalam diri manusia bukan untuk dirinya sendiri, tetapi juga untuk orang lain (other) yang termanifestasikan melalui eros. Konsep eros sangat penting dalam pemikiran Yannaras, karena menurutnya, manusia mencapai kesempurnaannya dalam gerak erotik kepada Allah (the supreme Othernees). ${ }^{36}$ Sementara itu, dengan menghubungkan person, eros, dan otherness, ia menggagas ontologi yang relasional. Otherness terwujud dan dikenali melalui relasi dengan yang lain (in-relation-to-the-other). Relasi tidak pernah terbatas dan bahkan sangat dinamis secara terus menerus. ${ }^{37}$

Mitralexis mengatakan bahwa pengalaman eklesial menyaksikan bahwa manusia diciptakan menurut citra Allah dan eksistensinya pun merupakan menegaskan manusia sebagai person. ${ }^{38}$ Pada titik ini, tampaknya Yannaras mempertahankan gagasan person, termasuk Allah dan manusia bahkan seluruh ciptaan menempatkan semuanya dalam relasi yang erotik.

\section{Persekutuan Ilahi-Manusia Sebagai Persekutuan Erotik}

Dalam bagian lain Person and Eros, Yannaras mengatakan bahwa dunia merupakan cara penyingkapan personal dari realitas fisik. Kata Yunani untuk dunia adalah kosmos yang berarti tatanan atau ornamen menentukan cara mengada realitas fisik tersebut. Kosmos (ordered) menyingkapkan beings. Sebab itu, ia juga mengimplikasikan keindahan

34 Yannaras, Person and Eros, 20.

35 Yannaras, 223.

36 Yannaras, 20.

37 Christos Yannaras, Relational Ontology (Brookline, Mass: Holy Cross Orthodox Press, 2011), 33.

38 Mitralexis, "Person, Eros, Critical Ontology," 38. 

dari keunikan (uniqueness) personal yang relasional. ${ }^{39}$ Penggunaan kata kosmos pada masa pre-Sokrates merujuk pada harmoni dan tatanan realitas fisik, bahkan merujuk pada penataan ruang publik. ${ }^{40}$ Dengan demikian, kosmos adalah cara cara mengada personal yang unik itu sendiri. Kosmos juga merupakan penampakan personalitas dari Allah (Being) yang menata dunia (decorum) dengan keunikan personal, sebagai representasi keindahan. Karya Allah juga terlihat dalam penataan ruang publik yang baik.

Yannaras meyakini bahwa ciptaan adalah hasil dari hasrat (baca: eros) Ilahi. Bahkan, mempersekutukan ciptaan dengan diri-Nya adalah hasrat ilahi juga. Ia mengatakan "Eros is dynamics of ecstasy, which finds its consummation as personal reference to supreme Otherness: divine eros is also ecstatic, so that the lovers belong not to themselves but to the beloved." 41 Sebab itu, eros selalu berupa invitasi untuk berpartisipasi dalam persekutuan dan relasi, suatu daya tarik untuk bersatu. Eros juga menyingkapkan keterbatasan dan kelemahan dari manusia dalam merespons panggilan untuk memenuhi persekutuan dan relasi dan dunia. $^{42}$

Gereja, sebagai umat Allah, bukan semata-mata institusi atau perkumpulan sejumlah orang yang memiliki pemikiran yang sama, melainkan sebagai sebuah realitas (being). Artinya, gereja dan setiap anggotanya adalah person..$^{43}$ Gereja baginya adalah persekutuan makan Paska atau persekutuan ekaristik yang dialami dalam hari kebangkitan. ${ }^{44}$ Sementara hari-hari biasa merupakan perayaan akan kelahiran baru yang di dalamnya setiap person berpartisipasi di dalam perayaan dan kesukacitaan gereja tersebut. Partisipasi person berarti meninggalkan arogansi individualitas dan taat kepada Kristus serta merayakan keunikan dan kebebasan. ${ }^{45}$ Dalam tulisannya yang lain, Yannaras

39 Yannaras, Person and Eros, 73.

40 Yannaras, 73-74.

41 Yannaras, 20.

42 Yannaras, 83.

43 Kaniaru, "Rethinking Rationality: Theological Anthropology in light of Profound Cognitive Impairment, Relationality, Embodiment and Personhood," 101.

44 Yannaras, Elements of Faith, 123.

45 Yannaras, The Freedom of Morality, 107. 

hanya percaya kepada cinta Allah dan menjaga pengharapan tersebut tetap hidup. Kepercayaan penuh semacam inilah, menurut Yannaras, bentuk lain dari pengetahuan yang dihasilkan dari relasi cinta. ${ }^{46}$ Gereja merespons panggilan Allah untuk menyadari keberadaannya dalam hubungan dengan-Nya. Keberadaannya hanya didefinisikan sebagai sebagai kerinduan untuk hidup dalam relasi dengan Allah. ${ }^{47}$ Kerinduan yang disebutkan Yannaras pun harus dibaca sebagai hasrat eros kepada Allah. Hasrat untuk merespons panggilan Allah.

Keterbatasan dari percakapan ontologis semacam ini adalah kurangnya realisme terhadap konteks yang real. Artinya, percakapan ini tidak melibatkan atau berdialog dengan persoalan sosial dan politik. Persoalan ini tampak direspons dengan serius oleh Yannaras. Menurut Jonathan Cole, pemikiran Yannaras tentang person dan eros merupakan responsnya terhadap ontologi Barat atau anti-westernisme. Menurut Yannaras, sebagaimana dipaparkan oleh Cole, bahwa ontologi Barat terlalu berorientasi pada individualisme, utilitarianisme, kebebasan memilih dan privasi. Sebab itu, ia mengusulkan gagasan ontologi relasi melalui personhood, komunitas, relasi dan persekutuan dengan Allah. ${ }^{48}$

\section{MENDIALOGKAN TEOLOGI HARI KEDELAPAN DENGAN PEMIKIRAN YANNARAS}

Menghasrati Hari Kedelapan dalam Persekutuan Erotik Ilahi-Manusia

Dalam Element of Faith, Yannaras menjelaskan secara khusus tentang konsep hari Kedelapan. ${ }^{49}$ Ia mengatakan bahwa gereja menantikan kebangkitan dari kematian dan menantikan kehidupan dari dunia yang akan datang. Dunia kini yang rusak akan dipulihkan. Ia sendiri menolak bahwa dunia akan dihapuskan dan akan diganti dengan dunia yang baru.

46 Christos Yannaras, "Eschatology: End of Time or Freedom from Time" (14 November 2005), 1.

47 Yannaras, 3.

48 Jonathan Cole, “The Problematic of Greek Identity and Christos Yannaras' Quest for a Politics of Authentic Existence," dalam Polis, Ontology, Ecclesial Event. Engaging with Christos Yannaras' Thought., ed. oleh Sotiris Mitralexis, Pui Him Ip, dan Isidoros Katsos (Cambridge: James Clarke \& Co. Ltd, 2018), 13.

49 Yannaras, Elements of Faith, 118. 

Menurutnya, penciptaan ulang tersebut akan terjadi pada hari Kedelapan. Sebuah hari yang bertolakbelakang dengan hari-hari biasa. Hari Kedelapan mengindikasikan kondisi yang melampaui ruang dan waktu. Semua manusia akan mengambil bagian dalam kebangkitan Kristus dan dipersatukan dengan Allah (theosis). Gereja sendiri adalah pen-ultima dari penyempurnaan hari Kedelapan. Gereja adalah "permulaan" dan "janji" dari kemulian di masa depan. Ia hidup dengan membagikan kehidupan tersebut, mentransformasikan individu (anti-relasi) ke dalam relasi yang saling mencintai (ekaristi, disiplin spiritual, dan liturgi). ${ }^{50}$

Pada bagian ini, Yannaras menegaskan nisbah antara Hari Kedelapan dengan eros. Menurutnya, cinta Allah menemukan manusia melalui cinta-Nya yang berbela rasa (compassionate love: eros) dan Allah Sang Eros tidak akan meninggalkan orang yang dicintainya menjadi tidak ada (non-existence) (Rom. 4:17). ${ }^{51}$ Dalam Person and Eros, Yannaras semakin menegaskan nisbah keduanya, meskipun hanya sedikit. Ia mengatakan bahwa Hari Kedelapan berimplikasi pada relasi Allah dengan manusia dalam persekutuan yang erotik. ${ }^{52}$ Tampaknya, Yannaras menegaskan bahwa wajah seluruh kekristenan adalah wajah partisipasi erotik.

Dengan demikian, menghasrati Hari Kedelapan berarti merespons gerak erotik Allah pada manusia. Hari tersebut juga simbol eros ilahi yang tertinggi, yakni dalam penebusan, kebangkitan, dan Kerajaan Allah. Respons erotik tersebut juga dipraktikkan pada dunia (kosmos) yang juga merupakan penyingkapan eros Allah. Implikasi lain dari elaborasi ini adalah eko-teologi. Pada bagian lain dalam Person and Eros, Yannaras mengelaborasi pemikiran Maximus the Confessor, terutama dalam relasinya dengan partisipasi gereja dalam menjaga alam. Tentu saja, percakapan ini dapat dielaborasi lebih jauh dalam riset yang berbeda. Pada bagian selanjutnya, saya akan menegaskan respons erotik terhadap dunia adalah bentuk mempersembahkan diri (self-offering) kepada Allah dan dunia.

50 Yannaras, 118-19.

51 Yannaras, 120.

52 Yannaras, Person and Eros, 153. 
Sebagaimana telah dipaparkan di atas bahwa Hari Kedelapan, salah satunya dipahami sebagai penciptaan baru di dalam Kristus. Dengan menggunakan perspektif Yannaras, kebangkitan Kristus tersebut dapat dipahami sebagai kebangkitan yang erotik. Artinya, kebangkitan Kristus adalah gerak erotik Allah pada ciptaan. Dalam Element of Faith, Yannaras mengatakan bahwa Allah, di dalam Kristus, mempersembahkan diriNya untuk membarui seluruh ciptaan agar dapat berpartisipasi ke dalam keilahian. ${ }^{53}$ Secara eskatologis, Hari Kedelapan dipandang sebagai hari kebangkitan Kristus, sekaligus imaji terhadap Kerajaan Allah yang ada di masa depan. Sebab itu, Hari Kedelapan dapat dipandang sebagai gerak proleptik sekaligus erotik Allah kepada dunia. Terkait implikasi politik dari gerak proleptik Allah, saya hendak meminjam penjelasan dari Pantelis Kalaitzidis. Menurutnya, persekutuan mistik ilahi-ciptaan dalam ekaristi sebagai inti dari Hari Kedelapan harus terverifikasi dalam dinamika sosial dan memanifestasikan Kerajaan Allah untuk berjuang melawan tindakan kejahatan dan mengubah dunia. ${ }^{54}$ Dengan demikian, dimensi erotik gerak prolektik Allah justru menegaskan kehadirannya dalam dinamika sosial. Allah secara erotik mengupayakan dunia yang baru, yakni Kerajaan-Nya, dan ditandai dengan kebangkitan Kristus. Selanjutnya, jika Kristus adalah persembahan diri Allah (self-offering), maka secara ontologis, gereja juga adalah realitas yang erotik. Sebagai realitas komunal, partisipasi gereja dalam kehidupan baru (New Aeon) dilakukan secara erotik.

Bapa-bapa Gereja yang telah dipaparkan di atas mengelaborasi eskatologi Hari Kedelapan dalam wajah kesehariaan berdasarkan watak kekekalan dan sirkularitas. Dengan demikian, partisipasi erotik gereja semestinya terjadi dalam ruang-ruang keseharian. Dalam bukunya Freedom and Morality, Yannaras mengatakan bahwa etos gereja adalah etos komunal atau sosial. Sebab itu, komunalitas gereja merupakan

53 Yannaras, Elements of Faith, 119.

54 Pantelis Kalaitzidis, "Eastern Orthodox Thought," dalam The Blackwell Companion to Political Theology, ed. oleh Peter Scott, Blackwell Companions to Religion (Malden: Blackwell, 2004), 102. 

manifestasi dari person dan eros gereja. Persekutuan merupakan konstitusi kehidupan. Dengan kata lain eksistensi gereja hanya mungkin melalui persekutuan itu sendiri. Penyebab dan sumber dari gerak erotik dari Allah Trinitas. Sebab itu, realitas ontologis gereja adalah gerak erotik. ${ }^{55}$ Lebih lanjut, Yannaras mengatakan: "For the Church, communion is an ontological fact: not the consequence of the ontological fact, but a fact essential to being. The historical fact that people live together in groups and the phenomenology of what is call "communal" or "social" life the political, social, economic and governmental organization of human groups - is only one expression of this fact." 56

Yannaras tampak lebih jauh lagi menarik percakapan realitas ontologi gereja yang komunal pada percakapan ruang publik yang sangat multidimensi. Eksistensi gereja sebagai sebuah komunitas pada saat yang sama adalah realitas metafisik dan politis dalam keseharian. ${ }^{57}$ Artinya, gereja juga adalah realitas politis. Sebab itu, partisipasi dalam penataan ruang publik harusnya merupakan tindakan erotik.

Jika personalitas dan eros adalah perkara aktualitas diri terhadap The Supreme Other, maka dalam konteks ruang publik keduanya dapat dipahami sebagai model kehadiran untuk sang liyan atau person-person lain. Yannaras tidak menjelaskan secara spesifik tentang siapa yang dimaksud others. Namun, menurut saya, others dalam hal ini harus diinterpretasikan sebagai orang-orang yang terpinggirkan dan mengalami ketidakadilan. Interpretasi tersebut cukup beralasan, mengingat penggunaan terma person sebagai antitesis terhadap individulitas yang anti relasional. Konteks percakapan Yannaras pun memang sedang melabrak ontologi Barat yang sangat individulialis, utilitarian, kekebasan individu, dan privasi. Percakapan ontologi semacam ini pada akhirnya menegasikan eksistensi Sang Liyan. Pada titik inilah, Yannaras setuju dan bahkan meminjam pemikiran Martin Heidegger.

55 Yannaras, The Freedom of Morality, 211.

56 Yannaras, 211.

57 Sotiris Mitralexis, "The Eucharistic Community is Our Social Program: On the Early Development of Christos Yannaras' Political Theology," Political Theology 0, no. 0 (28 November 2017): 11. 
Terkait dengan pengalaman dengan sang liyan, saya hendak meminjam pemikiran Richard Kearney tentang mikro-eskatologi. Dalam mengelaborasi tema ini, Kearney juga menggunakan konsep prosopon. Prosopon merupakan sang liyan yang menantikan respons dalam situasi yang nyata. Maka, mikro-eskatologi adalah esensi, being, dan anugerah nyata dalam perjumpaan keseharian dengan sang liyan (prosopon) ${ }^{58}$ Eskatologi bagi Kearney bukan tujuan, tetapi kemungkinan-kemungkinan di masa depan yang tidak dapat diwujudnyatakan. ${ }^{59}$ Tampaknya, atas keyakinan bahwa eskatologi sebagai sesuatu yang mustahil, ia menyiasatinya dengan gagasan mikro-eskatologi. Sepemahaman dengan Keaney, hari-hari biasa yang mengakar (ataupun dapat dipahami sebaliknya, bahwa Hari Kedelapan meresap ke dalam hari-hari biasa) pada Hari Kedelapan sesungguhnya mengalami mikro-eskatologi. Pengalaman yang menjumpai sang liyan itu hanya dimungkinkan dalam relasi erotik.

\section{KESIMPULAN: MENGHASRATI SANG AKHIR, MEMPERSEM- BAHKAN DIRI PADA DUNIA}

Sebagai catatan penutup, bagaimanakah gereja dapat menghasrati Hari Kedelapan dan mempersembahkan diri? Gereja harus menyadari natur erotiknya. Nindyo Sasongko, dalam “Eros, Eklesia, dan Resistensi," mengatakan bahwa gereja perlu memeluk kembali konsep eros dan menyadari natur erotiknya. ${ }^{60}$ Sebab itu, gereja sebagai tubuh Kristus menyoal kehadiran yang erotik sekaligus ek-statik. Komunitas yang keluar dari dirinya. Teolog-teolog lain misalnya, Roger Haight mengusulkan ide ecclesial existence. Menurutnya, gereja harus sepenuhnya hadir dalam masyarakat. Gereja tidak dapat terpisah dari dunia. Walaupun natur gereja dapat didefinisikan secara abstrak, tetapi kehadirannya harus berkelindan secara konkrit dan menyejarah dalam dunia. Menariknya, Haight

58 Richard Kearney, "Epiphanies of the Everyday: Towards a Micro-Eschatology," dalam After God: Richard Kearney and the religious turn in continental philosophy, ed. oleh John Panteleimon Manoussakis, 1st ed, Perspectives in continental philosophy series, no. 49 (New York: Fordham University Press, 2006), 3-20.

59 Richard Kearney, The God Who May Be: a Hermeneutics of Religion, Indiana series in the philosophy of religion (Bloomington: Indiana University Press, 2001), 12.

60 Sasongko, "Eros, Eklesia, dan Resistensi: Sebuah Eksplorasi Konstruktif-Misiologis Peran Gereja di Ruang Publik," 266. 

mengusulkan agar nilai kemanusiaan sebagai bagian dari respons kepada Allah. ${ }^{61}$ Ia memberikan ruang yang besar pada dimensi kebebasan manusia untuk merespons gerak Allah.

Demikian pula, Joas Adiprasetya mengusulkan gagasan diaklesia atau gereja terbuka-rapuh yang melintasi batas-batas dan berjumpa dengan orang miskin. ${ }^{62}$ Mereka menegaskan pentingnya kehadiran gereja. Saya memahaminya sebagai wujud dari keseharian Hari Kedelapan dan gerak erotik terhadap dunia. Akhirnya, peran publik gereja adalah bentuk persembahan diri (self-offering) terhadap kemaslahatan orang banyak. Dengan mengakar pada Hari Kedelapan, maka melalui hari-hari biasa gereja semakin dapat menandaskan kehadirannya (mode of existence) secara erotik. Gerak erotik tersebut sekaligus ekspresi erotik atau menghasrati Allah Sang Akhir.

\section{DAFTAR ACUAN}

Adiprasetya, Joas. "Poverty Reduction in the Contexts of Asia and Indonesia in Particular: An Ecclesiological Perspective." dipresentasikan pada International Community of Diaconic Management - UEM, Sekolah Tinggi Filsafat Theologi Jakarta, 2018.

Baghos, Mario. "St Basil's Eschatological Vision: Aspects of the Recapitulation of History and the 'Eighth Day.'” Phronema 25 (2010): 85-103.

Basil. On the Holy Spirit. Diterjemahkan oleh Stephen M. Hildebrand. Popular Patristics Series, no. 42. Yonkers, N.Y: St. Vladimir's Seminary Press, 2011.

Cole, Jonathan. "Personhood, Relational Ontology, and the Trinitarian Politics of Eastern Orthodox Thinker Christos Yannaras." Political Theology 0, no. 0 (22 Februari 2017): 1-14.

. "The Problematic of Greek Identity and Christos Yannaras' Quest for a Politics of Authentic Existence." Dalam Polis, Ontology, Ecclesial Event. Engaging with Christos Yannaras' Thought., disunting oleh Sotiris Mitralexis, Pui Him Ip, dan Isidoros Katsos, 47-63. Cambridge: James Clarke \& Co. Ltd, 2018.

61 Roger Haight, Christian Community in History. Vol. 3: Ecclesial Existence, Pbk. ed (London: Bloomsbury, 2014), 265.

62 Joas Adiprasetya, "Poverty Reduction in the Contexts of Asia and Indonesia in Particular: An Ecclesiological Perspective" (2018), 4. 
Daniélou, Jean. The Bible and the Liturgy. 1 ed. Notre Dame, Indiana: University of Notre Dame Press, 2002.

Haight, Roger. Christian Community in History. Vol. 3: Ecclesial Existence. Pbk. ed. London: Bloomsbury, 2014.

Justin. Dialogue with Trypho. Disunting oleh MichaelSlusser. Diterjemahkan oleh Thomas B. Falls. Selections from the Fathers of the Church, v. 3. Washington, D.C: Catholic University of America Press, 2003.

Kalaitzidis, Pantelis. "Eastern Orthodox Thought." Dalam The Blackwell Companion to Political Theology, disunting oleh Peter Scott, 95-110. Blackwell Companions to Religion. Malden: Blackwell, 2004.

Kaniaru, Antony. "Rethinking Rationality: Theological Anthropology in light of Profound Cognitive Impairment, Relationality, Embodiment and Personhood." Doctoral Dissertation, Durham University, 2012.

Kearney, Richard. "Epiphanies of the Everyday: Towards a Micro-Eschatology." Dalam After God: Richard Kearney and the religious turn in continental philosophy, disunting oleh John Panteleimon Manoussakis, 1st ed., 3-20. Perspectives in continental philosophy series, no. 49. New York: Fordham University Press, 2006.

The God Who May Be: a Hermeneutics of Religion. Indiana series in the philosophy of religion. Bloomington: Indiana University Press, 2001.

Louth, Andrew. "Introduction." Dalam On the Absence and Unknowability of God: Heidegger and the Areopagite, oleh Christos Yannaras, diterjemahkan oleh Haralambos Ventis, 2nd ed. London, New York: T \& T Clark International, 2005.

Mitralexis, Sotiris. "Person, Eros, Critical Ontology: An Attempt to Recapitulate Christos Yannaras' Philosophy." Sobornost 34, no. 1 (2012): 33-40.

. "The Eucharistic Community is Our Social Program: On the Early Development of Christos Yannaras' Political Theology." Political Theology 0, no. 0 (28 November 2017): 1-20.

Moltmann, Jürgen. God in Creation: A New Theology of Creation and the Spirit of God. London: SCM Press Ltd, 1985.

Pannenberg, Wolfhart. Systematic Theology. A\&C Black, 2004.

Roberts, Alexander, James Donaldson, A. Cleveland Coxe, dan Allan Menzies. Ante-Nicene Fathers: The Writings of the Fathers down to A.D. 
240 Menghasrati Sang Akhir, Mempersembahkan Diri pada Dunia (Ch. Sema Rappan P.) 325. Peabody, Mass.: Hendrickson Publishers, 1994.

Sasongko, Nindyo. "Eros, Eklesia, dan Resistensi: Sebuah Eksplorasi Konstruktif-Misiologis Peran Gereja di Ruang Publik." Dalam Misiologi Kontemporer: Merentangkan Horison Panggilan Kristen, disunting oleh C.S. Rappan Paledung, Nindyo Sasongko, dan Indah Sriulina, 243-70. Jakarta: BPK Gunung Mulia \& Asosiasi Teolog Indonesia, 2019.

Schaff, Philip. Nicene and Post-Nicene Fathers, 2nd Series, vol. VIII: St. Basil: Letters and Select Works. Eerdmans, 1968.

Schaff, Philip, Alexander Roberts, James Donaldson, dan A. Cleveland Coxe. Ante-Nicene Fathers, 2017.

Schmemann, Alexander. For the life of the world: sacraments and orthodoxy. Crestwood, N.Y: St. Vladimir's Seminary Press, 2004.

Introduction to Liturgical Theology. Crestwood, N.Y: St. Vladimir's Seminary Press, 2003.

Williams, Rowan. "The Theology of Personhood: A Study of the Thought of Christos Yannaras." Sobornost 6 (1972): 415-30.

Yannaras, Christos. Elements of Faith: An Introduction to Orthodox Theology. Edinburgh: T \& T Clark, 1991.

. "Eschatology: End of Time or Freedom from Time." Moscow, 14 November 2005.

. Person and Eros. Diterjemahkan oleh Norman Russell. Brookline, Mass: Holy Cross Orthodox Press, 2007.

Relational Ontology. Brookline, Mass: Holy Cross Orthodox Press, 2011.

The Freedom of Morality. Contemporary Greek Theologians, no. 3. Crestwood, N.Y: St. Vladimir's Seminary Press, 1984.

Zizioulas, John D. Being as communion: studies in personhood and the church. Contemporary Greek theologians, no. 4. Crestwood, N.Y: St. Vladimir's Seminary Press, 1985.

. The Eucharistic Communion and the World. London; New York: T \& T Clark, 2011. 